\title{
REALITAS PERILAKU BERAGAMA KOMUNITAS TUKANG SAMPAH DI KELURAHAN GUNUNGSARI KECAMATAN RAPPOCINI KOTA MAKASSAR
}

\author{
Abdul Azis Muslimin, Baharuddin \\ Universitas Muhammadiyah Makassar \\ abdazizm@unismuh.ac.id, baharuddin@unismuh.ac.id
}

\section{Abstrak}

Tujuan penelitian ini untuk mengetahui dan menganalisis perilaku beragama komunitas tukang sampah, dan peran Stake Holder terahadap pembinaan keagamaan bagi masyarakat miskin, khususnya komunitas tukang sampah di di Kelurahan Gunung Sari Kecamatan Rappocini Kota Makassar.Jenis penelitian ini yaitu kualitatif dengan metode analisis deskriptif menggunakan pendekatan fenomenologi. Sasaran penelitian ini dilakukan dengan mengamati pekerjaan tukang sampah pada sore hingga malam hari saat mobil kontainer datang, dan terdapat sekitar 13 orang yang beraktivitas mengisi kontainer dari sampah-sampah yang diambil dari rumah ke rumah di wilayah kerjanya masing-masing pada beberapa RT/RW. Jenis data yang digunakan meliputi, data primer, yaitu data yang diperoleh di lapangan melalui wawancara secara mendalam terhadap para informan. Data sekunder, yaitu data yang diperoleh dari dokumen-dokumen yang terdapat pada Pemerintah Kelurahan Gunung Sari Kota Makassar. Fokus Group Discussion (FGD), kegiatan ini dilaksanakan di bawah koordinasi Pemerintah Kelurahan Gunung Sari Kecamataan Rappocini Kota Makassar.Hasil penelitian menunjukkan bahwa perilaku beragama komunitas tukang sampah di Kelurahan Gunung Sari Kecamataan Rappocini Kota Makassar sangatlah pragmatis yang ditandai dengan sederhana sekali mereka memaknai beragama. Bekerja sebagai tukang sampah adalah sebuah pilihan yang tak terelakkan bagi eksistensi masyarakat miskin seperti ini yang menjadi konsep equilibrium masyarakat perkotaan karena sektor informal yang mereka sentuh sangat mustahil disentuh oleh kelompok borjuis ataupun konglomerat serta masyarakat ekonomi atas, dan kehadiran stake holder yang intens dan fokus kajiannya ke masalah sosial ini sangat diperlukan sebagai upaya memenuhi kebutuhan spiritual mereka. Universitas Muhammadiyah sebagai sebuah Perguruan Tinggi bercirikan keagamaan, sangat harus menjadikan bentuk pengamalan Tridarma Perguruan Tinggi dengan melakukan ekspansi pembinaan keagamaan bagi komunitas seperti ini, apalagi perguruan tinggi ini berada dalam wilayah Kecamatan Rappocini.

Kata kunci: Tukang sampah, Perilaku Beragama

\section{Abstrac}

The purpose of this research to review and analyze the behavior of religious community garbage man, and role of stakeholders terahadap religious training for the poor, especially the garbage men in Rappocini in Gunung Sari village cider in the City of Makassar.

Type this research qualitative analysis method use phenomenology descriptive approach. Target this report is written by observing work garbage man in the afternoon until night car come when container, and there are around 13 one who fill from garbage exertion container taken from house to house in their respective work areas in several RT/RW. Types of data on used covering, primary data, the data obtained in the field through interviews deeply to the informants.Secondary data, the data obtained of documents that is in the government Gunung 
Sari Makassar City. Focus group discussion (FGD ), this activity was carried out under the coordination of sub-district government Gunung Sari kecamatan rappocini makassar city. The research results show that religious behavior community garbage man in gunung sari Kecamataan Rappocini City of Makassar very pragmatic characterized by simple once they perceive. Religious working as a trash is an option that inevitable for existence of poor people like this be punctuated the urban community because the informal sector they touch highly improbable touched by the bourgeois or economic as well as the conglomerate top, and the presence of stakeholders and the focus of intense kajiannya to social issues is really needed in order to meet the needs of their spiritual.Muhammadiyah University as a college, characterized by religious should make the very sent Tridarma College with had expanded coaching, religious communities like this let alone college were inside subdistricts Rappocini is.

Key words: garbage man religious behavior

\section{LATAR BELAKANG}

Kota besar selalu menjadi daya tarik tersendiri bagi kaum urban yang umumnya berasal dari pedesaan. Gemerlapnya lampu dan kehidupan malam sungguh memukau mata pendatang yang terbiasa menikmati gelapnya malam ditemani alunan suara jangkrik nan menyayat hati. Pesatnya pembangunan infrastruktur tentunya membutuhkan banyak pekerja, namun, ketersediaan lahan pekerjaan yang tersedia tidak sebanding dengan harapan mereka karena sumber daya manusia mereka kurang atau tidak relevan, sehingga banyak yang hanya dapat bekerja secara informal di perkotaan dan pengangguran cukup besar. Bahkan, kemiskinan dipandang sebagai bagian dari struktur sosial dengan kekuatan yang menginginkannya tetap eksis. Mereka menyentuh ruang-ruang informal yang bisa dikatakan tidak pernah disentuh oleh kelompok borjuis/kaya, bahkan kehadiran pekerja miskin telah menciptakan equilibrium dalam sistem sosial masyarakat, khususnya di Kota Makasssar.

Lingkungan sosial akan membentuk sikap seseorang yang seringkali diwujudkan dalam bentuk tindakan sehingga mempengaruhi nilai-nilai dalam perilaku kesehariannya, namun mereka senantiasa fokus pada kerjakerja untuk memenuhi kebutuhan dasar (fisiologis). Abraham Maslow dalam Abustam (1995) menyebutkan bahwa kebutuhan tiap manusia tumbuh secara progresif yaitu ketika kebutuhan tingkat terendah terpuaskan, maka individu bersangkutan mencari kebutuhan berikutnya yang lebih tinggi lagi sampai yang tertinggi. Tentunya semua pihak memiliki kebutuhan, namun yang jadi persoalan adalah bagaimana memenuhi kebutuhan dasar yang utama, padahal kemiskinan berimplikasi pada cara pandang mereka dalam memenuhi kebutuhannya sehingga bertindak pragmatis.

Realitas tersebut menunjukkan bahwa setiap orang dipandang tidak pernah puas hanya dengan satu atau beberapa kebutuhan saja. Hirarki kebutuhan individu mulai dari terendah yaitu kebutuhan fisik, kebutuhan rasa aman, sosial, harga diri, sampai yang tertinggi yaitu aktualisasi diri. Namun, bagi sebagian orang kemiskinan melunturkan nilai-nilai harga diri, padahal setiap individu dari strata apapun harga diri ditempatkan sebagai unsur yang utama. Fenomena kemiskinan menjadi sebuah “catatan' bahwa masyarakat miskin perkotaan 
mengkhususkan diri mereka sebagai kelompok yang senantiasa mengharapkan bantuan dari pihak lain. Perilaku sebagian masyarakat seringkali memanfaatkan momen kemiskinan, lalu bermetamorphosis dengan pola hidup pragmatis di perkotaan seperti menjadi tukang sampah yang tidak membutuhkan Ijazah dan sekolah yang tinggi.

Perilaku miskin diturunkan dari satu generasi kegenerasi lainnya dalam lingkaran kemiskinan "budaya kemiskinan”. Belum lagi perilaku masyarakat kota yang pragmatis dalam menyalurkan sedekah ataupun bantuan lainnya di jalanan, karena mereka tidak mau repot dan senantiasa berpikiran bahwa diatelah bersedekah walaupun itu justru tidak memberikan efek pendidikan yang baik kepada para tukang/ pemungut sampah. Tukang sampah merasakan takdirnya miskin yang harus dijalani dan bukan diratapi untuk dapat eksis di perkotaan, maka menjadi tujkang sampah adalah sebuah pilihan. Perilakunya sangat sederhana dengan menekuni profesinya, namun banyak diantara mereka seringkali mengabaikan aspek-aspek ibadah ataupun pembinaan keagamaan.

Semakin banyak jumlah orang miskin, maka potensi tukang/ pemungut sampahpun bertambah. Dengan demikian di maknai bahwa motivasi mereka beraktivitas tidaklah berorientasi prestasi seperti yang dikemukakan oleh Mc Clelland tapi sesuatu yang instan. Tukang sampah di Kota Makassar di dominasi oleh kaum urban yang searah dengan tipologi musiman, yaitu tukang/ pemungut sampah yang saat-saat tertentu saja mereka hadir di Kota Makassar baik secara berkelompok ataupun secara individu pada momen bulan ramadhan, hari raya idul fitri dan idul adha, hari jum'at, imlek ataupun tahun baru. Perilaku sosial yang mereka munculkan tentunya mendapatkan simpati dan antipati dari beberapa pihak, dan sikap pragmatisme berpikirlah yang menggiring mereka untuk berkompetisi di Kota Makassar dalam mendapatkan rezeki. Namun tidak tertutup kemungkinan terjadinya perubahan status dari tukang/ pemungut sampah temporer menjadi tukang/ pemungut sampah permanen sebagai sebuah pilihan dalam eskalasi pemenuhan kebutuhan fisiologis.

Visi Walikota Makassar sangat elegant dengan menekankan Makassar Ciber City yang juga bahwa bahwa Makassar dibangun dari lorong dan kotanya harus menjadi bersih hingga berhasil meraih Piala Adipura sebagai supremasi kota bersih sehingga diharapkan Kota Makassar tetap indah, aman, bersih dan teknologi digital menjangkau seluruh kawasan Kota Makassar dan untuk mewujudkannya, maka semua stake holder dibriefing dan dibekali bagaimana mewujudkan visi tersebut. Cukup terasa bagi warga Kota Makassar tentang penanganan sampah yang selalu terlambat dan, kacau, kotor serta berbau.

Namun, saat ini semua itu hanya tinggal cerita karena sampah-sanpah tidak lagi diparkir di beberapa sudut akibat kritikan warga sekitar penitipan kontainer dan sering juga terhambur. Langkah jitu dengan mengubah pola penjemputan sampah menggunakan pekerja khusus yang beroperasi dari tiap RT/RW untuk melakukan penjemputan dengan menggunakan motor Viar atau Fukuda pada malam hari mulai jam 19 hingga 20.30 dan Mobil kontainer ready jam 20-22 malam di pangkalan yang telah ditentukan. Realitas tersebut menjadi perhatian peneliti karena aktivitas mereka itu menjadikan 
sebagian mereka tidak lagi beriteraksi dengan "Tuhan", aktivitas ekoniomi yang mereka lakonkan seringkali mengabaikan prinsipprinsip keagamaan, misalnya shalat dan puasa.

Lemahnya kontrol pemerintah pada sektor ini menjadi perhatian serius untuk lebih meningkatkan kinerja mereka yang tidak hanya dengan ukuran pendapatam ekonomi tapi juga dengan pembinaan keagamaan. Dimensidimensi seperti inilah yang agak sulit disentuh oleh Pemerintah Kota Makassar sehingga dipandang perlu untuk melakukan kerja sama ataupun adanya MOU dengan instansi terkait (stake holder) yang menggeluti bidang tersebut seperti lembaga-lembaga pendidikan berbasis agama seperti Fakultas Agama Islam Universitas Muhammadiyah Makasssar yang berada dalam wilayah penelitian.

\section{LANDASAN TEORI}

Charles Adams dalam Suparlan (1993:61) mengemukakan bahwa manusia menuju ke perkotaan karena di kota tersedia segalanya dan kenyataan lain orang berbondong-bondong ke perkotaan lebih cepat dari kesanggupan industri untuk menampung tenaga kerja. Fenomena tersebut menjadikan masyarakat urban tersebut melakoni perkerjaan yang dalam pikiran mereka bisa menghasilkan uang, termasuk pekerjaan-pekerjaan yang menyimpang.

Belum lagi dengan keterbatasan sumber daya yang dimiliki tentunya menjadikan mereka harus berpikir untuk bisa atau tidak dalam kompetisi kerja yang sangat menekankan individual skill. Namun bagi mereka yang memiliki semangat kerja tinggi dan jiwa petarung, tentunya keterbatasan sumber daya ataupun keterampilan yang dimiliki tidak menjadi masalah utama karena asal mau berusaha pastinya di kota mereka dapat memperoleh pekerjaan walaupun tidak sesuai dengan keterampin atau tidak membutuhkan keterampilan. Kehidupan dan pekerjaan di perkotaan tidak semuanya menekankan sumber daya, tapi juga kemauan dan kekuatan phisik misalnya jadi sopir mobil, tukang becak, buruh bangunan, kuli di pelabuhan, dagang kali lima yang kesemuanya itu tidak terlalu menekankan individual skill tapi kemauan.

Dalam kajian Sosiologi Perkotaan, Dieter Evers (1982:9) menguraikan tentang push and pull factors, dimana proses urbanisasi ke wilayah perkotaan dilatarbelakangi oleh kondisi ekonomi dan geografis di pedesaan. Disisi lain, kehidupan kota yang selalu dinamis berkembang dengan segala fasilitasnya yang serba gemerlapan, lengkap dan menarik serta "menjanjikan" tetap saja menjadi suatu "pull factor" orang mendatangi kota. Kota-kota besar menjadi sentral ekonomi dan industri yang semakin berorientasi ekonomi global sehingga mendorong perkembangan fisik dan sosial ekonomi.

Saat ini kota memiliki magnet dan sering menjadi tumpuan harapan masyarakat sehingga mereka berduyun-duyun berebut kesempatan untuk bisa memperoleh penghidupan di kota. Pesatnya perkembangan suatu kota ternyata juga membawa dampak sosial akibat tingginya iklim kompetitif. Selain itu, penyebab kaum urban yang berasal dari desa mengalami kehidupan yang semakin memburuk setelah tinggal di kota, yaitu disebabkan beberapa alasan antara lain menderita penyakit tertentu, kurangnya pendidikan, tidak mempunyai kemampuan 
untuk berkompetisi, kurang disiplin, puas pada keadaan, tidak mempunyai ketrampilan, relasi yang terbatas, penghasilan yang rendah. Hal tersebut mengakibatkan mereka yang tidak mampu bersaing dalam pekerjaan formal jadi betumpuh ke sektor pekerjaan informal salah satunya yaitu menjadi tukang/ pemungut sampah.

\section{METODE PENELITIAN}

Adapunjenispenelitianiniyaitukualitatif dengan metode analisis deskriptif menggunakan pendekatan fenomenologi. Dengan pendekatan ini peneliti dapat mengeksplorasi lebih dalam secara jelas dan tepat tentang pola penanganan dan pembinaan keagamaan terhadap tukang sampah di Kelurahan Gunungsari Kota Makassar. Penelitian ini dilakukan di Center Point atau tempat pertemuan motor Fukuda yang mengangkut sampah dari berbagai RT/ RW di Kelurahan Gunungsari untuk selanjutnya mengalihkan ke mobil sampah yang akan mengangkutnya ke tempat pembuangan akhir di wilayah Antang.

\section{HASIL PENELITIAN}

Realitas tersebut menunjukkan bahwa aktivitas memulung merupakan sebuah rutinitas keseharian mereka cukup padat dengan tuntutan ekonomi yang mengharuskan mereka bekerja maksimal. Hal tersebut mereka lakukan untuk memenuhi kebutuhan keluarga yang senantiasa bertambah, dan belum lagi dengan mereka yang telah berkeluarga.

Eksistensi mereka di Kota Makassar sebagian akibat dari dampak urbanisasi dan kemiskinan yang melanda mereka, apakah secara kultutral ataupun secara struktural.
Banyak diantara mereka tertarik ke kota karena melihat kota sebagai sumber kehidupan yang menjanjikan, namun di sisi lain mereka memiliki keterampilan yang sangat terbatas ataupun tidak sama sekali.

Menjadi pemulung ataupun tukang sampah menjadi pilihan sekaligus tantangan bagi sebagian orang, karena pekerjaan ini dominannya di perkotaan yang hampir tidak semua orang menjadikannya pilihan. Eksistensi mereka yang kadang mendapat cibiran dari kalangan atas, namun realitasnya mereka menjadi penopang kebersihan kota, khususnya di Kota Makassar. Kompleksitas permasalahan sosial di Makassar menuntut mereka agar lebih eksis pada kegiatan-kegiatan yang dapat berkontribusi pada pembangunan di wilayah perkotaan.

Realitas seperti ini sungguh membuat ironi, bahwa hal-hal yang seharusnya memerlukan suatu keadaan dan peralatan yang bersih ternyata berbaur dengan sampah dan keadaan yang kotor, apalagi terkait dengan aktivitas ibadah yang mungkin sebagian besar menafikkan hal tersebut. Sesuatu yang kontradiktif untuk diketahui dengan kesehatan yang mana seseorang manusia tentulah harus tetap sehat agar dapat melanjutkan hidup dengan lebih baik.

Pada dasarnya pembinaan keagamaan tidak ada dari pemerintah atau instansi terkait yaitu dinas kebersihan dan pemeritah kelurahan ataupun kecamatan dan hal ini terjadi di semua level kecamatan di Kota Makassar. Lemahnya peran pemerintah terhadap pekerja seperti ini menjadikan mereka hanya bekerja pada sektor ekonomi profit tanpa memperhatikan kebutuhan akhirat mereka. 
Urusan sembahyang itu adalah urusan kita masing-masing, kalau mau sembahyang ya sembahyang dan kalau tidak ya tidak sembahyang dan hal ini tidak menjadi keharusan oleh pengawas atau pemerintah bagi kami menjalankan salah satu rukun Islam, hanya satu yang ditegaskan pada kami untuk bekerja keras agar Kota Makassar bersih.

Lemahnya peran pemerintah terhadap pekerja seperti ini menjadikan mereka hanya bekerja pada sektor ekonomi profit tanpa memperhatikan kebutuhan akhirat mereka. Perilaku beragama dinampakkan dalam wujud beragama seperti sembahyang/shalat, puasa dan menghadiri peringatan hari besar islam (PHBI) di masjid dekat rumahnya. Ritual keagamaan yang dilakonkan hanya sebuah pelaksanaan ritual ibadah. Realitas tersebut menunjukkan bahwa kesederhanaan dalam memaknai agama sebagai sebuah doktrin dan pedoman hidup.

Dinamika kehidupan sosial perkotaan sangat dituntut dengan profesionalitas dalam bidangnya masing-masing, namun aspek ibadah menjadi sebuah hal determinan dalam konteks masyarakat modern yang memahami agama sebagai doktrin dan pedoman hidup. Realitas beragama yang harusnya dimaknai dengan simbolistik beribadah bukanlah hal determinan bagi kehidupan komunitas tukang sampah, karena bagi mereka beraktivitas adalkah hal pertama dan utama dalam sengkarut problematika perkotaan.

Namun demikian, sektor kebersihan kota dalah sebuah dimensi yang akan sangat sulit disentuh orang banyak, sehingga eksistensi mereka sangat dibutuhkan untuk mengequilibrium-kan tata kehidupan perkotaan. Persolannya dalah bagaimana mempolarisasi tata kehidupan masyarakat kota dnegan nilainilai religiusitas agar tercipta sebuah sistem yang bisa menghangatkan atmosfir beragama, termasuk bagi komunitas pemungut sampah di Kelurahan Gunung Sari.

\section{KESIMPULAN}

a. Perilaku beragama komunitas tukang sampah di Kelurahan Gunungsari Kota Makassar sangatlah pragmatis yang ditandai dengan perilaku yang sangat sederhana dalam beragama.

b. Bekerja sebagai tukang sampah adalah sebuah pilihan yang tak terelakkan bagi eksistensi masyarakat miskin sperti ini yang menjadi konsep equilibriumn masyarakat perkotaan karena sektor informal yang mereka sentuh sangat mustahil disentuh oleh kelompok borjuis ataupun konglomerat serta masyarakat ekonomi atas.

c. Kehadiran stake holder yang intens dan fokus kajiannya ke masalah sosial ini sangat diperlukan sebagai upaya memenuhi kebutuhan spiritual mereka. Fakuktas Agama Islam Universitas Muhammadiyah sebagai institusi pendidikan yang bercirikan keagamaan, sangat harus menjadikan bentuk pengamalan Tridarma Perguruan Tinggi dengan melakukan ekspansi pembinaan keagamaan bagi komunitas seperti ini, apalagi perguruan tinggi ini berada dalam wilayah Kecamatan Rappocini.

3. Saran dan Inovasi yang Ditargetkan Adapun target luaran dari penelitian ini akan menjadi acuan untuk:

a. Adanya ketegasan regulasi kebijakan Pemerintah Kota Makassar sebagai struktur terhadap pembinaan keagamaan 
pada masyarakat miskin, khususnya terhadap komunitas tukang sampah di Kelurahan Gunungsari Kota Makassar.

b. Universitas Muhammadiyah Makassar dan Fakultas Agama Islam secara khusus membuka akses dengan masyarakat sekitar kampus sebagai bagian dari Tri Darma Perguruan Tinggi, yaitu pengabdian pada masyarakat.

c. Merumuskan rekomendasi strategi kebijakan yang mendukung program pemerintah Kota Makassar pada sektor kebersihan kota dan pembinaan mental spiritual pada semua lapisan masyarakat.

\section{DAFTAR PUSTAKA}

Abustam, M. Idrus. Konsep Kemiskinan di Indonesia. Ujungpandang: Pusat Studi kependudukan, Universitas Hasanuddin, 1995.

Alfian, Kemiskinan Struktural Suatu Bunga rampai, Jakarta: Sangkala, 1984.

Garna, Judistira. Teori-teori Peruboahan sosial, Bandung; PPs Univ. Padjajaran, 1992.

Gans, Herbert J. Kebudayaan dan Kelas dalam Studi Mengenai Kemiskinan. Sebuah Pendekatan terhadap Penelitian Anti Kemiskinan; dalam Kemiskinan di Perkotaan di edit oleh Parsudi Suparlan, Jakarta-Sinar Harapan-yayasan obor.

Gilbert, Alan dan Josef Guller, Urbanisasi dan Kemiskinan di dunia ketiga, edisi terjemahan, Yogyakarta: Tiara Wacana. http://www.makassarkota.go.id/ profilpimpinan.html (diakses 5 Desember 2016), 2007.

Lewis, Oscar, Kebudayaan Kemiskinan; dalam Kemiskinan di Perkotaan, di edit oleh Parsudi Suparlan, Jakarta-Sinar Harapan-Yayasan Obor, 1983.

Raho, Bernaard. 2007. Teori Sosiologi Moderen, Jakarta: Prestasi Pustaka, 2007.

Poloma, Margaret M, Sosiologi Kontemporer. Jakarta: Raja Grafindo, 1994.

Ponsioen, J.A, The Analysis of Social Change Reconsidered: A Sociological Study, Third printing; Nederland: Mount, 1969

Ritzer, G dan Goodman Douglas J. Teori Sosiologi Modern. Terjemahan Alimandan. Jakarta: Prenada Media, 2005.

Ritzer, George. Ketika Kapitalisme Berjingkrak, Telaah Kritis terhadap Gelombang McDonaldisasi, edisi Terjemahan, Yogyakarta: Pustaka Pelajar, 2002.

Suharto. Edi, Kebijakan Sosial Sebagai Kebijakan Publik, Bandung: Alfabeta2007.

Suparlan, Parsudi. Manusia Indonesia: Individu, Keluarga dan Masyarakat Jakarta: Akademika Pressindo, 1986

\section{------------------. Kemiskinan di Perkotaan:} Bacaan untuk Antropologi Perkotaan, Jakarta: Yayasan Obor (ed), 1993.

Soekanto, Soejono. Max Weber: Konsepkonsep Dasar dalam Sosiologi. Jakarta: Rajawali, 1985. 
ISSN: 2085-2541

42 | BIDAYAH: Volume 11, No. 1, Juni 2020 